\title{
From Rare Species Detection to Whole-Community Diversity Using High-Throughput Sequencing of Freshwater eDNA
}

\author{
Maria Judite Alves, Hugo Gante ${ }^{\S}$, Ana Veríssimol, Filipe Ribeiro", Carlos David Santos ${ }^{\#}$, Sissel \\ Jentoft $^{\mathrm{a}}$ \\ ‡ cE3c - Center for Ecology, Evolution and Environmental Changes \& Museu Nacional de História Natural e da Ciência \\ Universidade de Lisboa, Lisboa, Portugal \\ $\S$ Indiana State University, Terre Haute, IN, United States of America \\ I CIBIO - Research Center in Biodiversity and Genetic Resources, Universidade do Porto, Porto, Portugal \\ II MARE - Marine and Environmental Sciences Centre, Universidade de Lisboa, Lisboa, Portugal \\ \# Núcleo de Teoria e Pesquisa do Comportamento, Universidade Federal do Pará, Universidade Federal do Pará, Belém, Brazil \\ a Centre for Ecological and Evolutionary Synthesis (CEES), Department of Biosciences, University of Oslo, Oslo, Norway
}

Corresponding author: Maria Judite Alves (․ㅣㄱㅣves@museus.ulisboa.pt), Hugo Gante (hugo.gante@indstate.edu)

Received: 04 Jul 2019 | Published: 10 Jul 2019

Citation: Alves MJ, Gante H, Veríssimo A, Ribeiro F, Santos CD, Jentoft S (2019) From Rare Species Detection to Whole-Community Diversity Using High-Throughput Sequencing of Freshwater eDNA. Biodiversity Information Science and Standards 3: e37975. https://doi.org/10.3897/biss.3.37975

\begin{abstract}
Understanding natural communities and ecosystems and the services they provide to humanity is highly dependent on knowledge about species composition and diversity through space and time. This is especially difficult in aquatic systems where traditional census methods provide species compositions that are usually truncated since rare species tend to go undetected. Detection of the rare species is important because they are either threatened or invasives at the earliest stage of invasion. One recent approach allowing detection of rare species uses environmental DNA (eDNA), present in water or soil, as traces of their existence.

Here we propose to make use of recent technological developments in the area of high throughput sequencing to characterize freshwater fish communities and detect rare species, using a combination of eDNA metabarcoding and bulk eDNA metagenomics. A case-study will be conducted on the River Tagus (Portugal), which is inhabited by several
\end{abstract}


rare fish species including both native and introduced taxa. In addition, the applicability of eDNA metagenomics for estimating the genetic diversity of populations will be assessed by comparing the results against those produced by traditional genetic screening of individual fish samples.

\section{Keywords}

eDNA metabarcoding; eDNA metagenomics

\section{Presenting author}

Maria Judite Alves

\section{Presented at}

Biodiversity_Next 2019

\section{Funding program}

02/SAICT/2017

\section{Grant title}

PTDC/BIA-CBI/31644/2017

\section{Hosting institution}

Museu Nacional de História Natural e da Ciência \& cE3c - Center for Ecology, Evolution and Environmental Changes \& MARE - Marine and Environmental Sciences Centre, Universidade de Lisboa, Portugal 